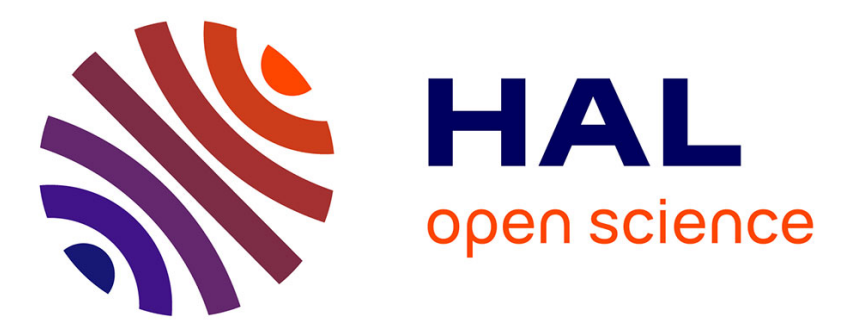

\title{
NQR detection of sodium nitrite recrystallized in wood
}

Jeremy Jover, Sarra Aissani, Laouès Guendouz, André Thomas, Daniel Canet

\section{To cite this version:}

Jeremy Jover, Sarra Aissani, Laouès Guendouz, André Thomas, Daniel Canet. NQR detection of sodium nitrite recrystallized in wood. NATO ARW workshop on magnetic resonnance detection of explosives and illicites materials, Sep 2012, Izmir, Turkey. hal-00777031

\section{HAL Id: hal-00777031 \\ https://hal.science/hal-00777031}

Submitted on 16 Jan 2013

HAL is a multi-disciplinary open access archive for the deposit and dissemination of scientific research documents, whether they are published or not. The documents may come from teaching and research institutions in France or abroad, or from public or private research centers.
L'archive ouverte pluridisciplinaire HAL, est destinée au dépôt et à la diffusion de documents scientifiques de niveau recherche, publiés ou non, émanant des établissements d'enseignement et de recherche français ou étrangers, des laboratoires publics ou privés. 


\title{
NQR DETECTION OF SODIUM NITRITE RECRYSTALLIZED IN WOOD
}

\author{
Jérémy Jover $^{(1),(3)}$, Sarra Aissani ${ }^{(1),(2)}$, Laouès Guendouz ${ }^{(2)}$, André Thomas ${ }^{(3)}$, Daniel Canet ${ }^{(1)} *$ \\ (1) Méthodologie RMN (CRM² ; UMR 7036, UL-CNRS), Université de Lorraine, Campus Aiguillettes, B.P. \\ 70239, 54506 Vandœuvre-lès-Nancy (cedex), France \\ (2) Lien, Université de Lorraine, Campus Aiguillettes, B.P. 70239, 54506 Vandœuvre-lès-Nancy (cedex), France \\ ${ }^{(3)}$ Cran, Université de Lorraine, Campus Aiguillettes, B.P. 70239, 54506 Vandœuvre-lès-Nancy (cedex), France \\ e-mail : daniel.canet@univ-lorraine.fr
}

\begin{abstract}
$\underline{\text { Abstract }}$
Cylindrical pieces of wood which can be placed in 10mm o.d. NMR sample tubes have been impregnated by an aqueous solution of sodium nitrite $\left(\mathrm{NaNO}_{2}\right)$. They were subsequently dried and examined by ${ }^{14} \mathrm{~N}$ quadrupole resonance. To our surprise, we were able to observe a signal at the right frequency $\left(4.64 \mathrm{MHz}\right.$, the highest frequency $\mathrm{NaNO}_{2}$ line). This implies that the material has been properly embedded but also that sodium nitrite was properly recrystallized. This latter point was more than speculative. Anyway, we could observe that it works for spruce, beech, ash, maritime pine, but not for oak (which is known to be difficult to impregnate). Instrumental parameters have been optimized for reducing the duration of the experiment. If the first measurements required around four hours, we obtain at the present time acceptable results in about four minutes or less.

In addition, we have designed a simple NLLS (Non Linear Least Squares) algorithm by which the spectral parameters of the NQR signal can be retrieved even if the peak is hardly visible in the frequency domain.

Extensive measurements have been performed on $\mathrm{NaNO}_{2}$ recrystallized in spruce. They show, among other things, that the totality of $\mathrm{NaNO}_{2}$ which has penetrated the material has actually recrystallized and seemingly for ever. Various assays have been carried out as a a function of impregnation and drying conditions. The evolution of the width of the $\mathrm{NaNO}_{2}$ line reflects defects in the crystal lattice of $\mathrm{NaNO}_{2}$ due probably to alteration of the wood structure.
\end{abstract}




\section{Introduction}

This work represents an attempt for detecting by NQR a molecule which has been imbedded in wood, the far-off objective being material labelling. In fact, our objective is rather to demonstrate the feasibility of this approach. Moreover, because we are familiar with ${ }^{14} \mathrm{~N}$ quadrupole resonance, we have focused on this quadrupolar nucleus in spite of its low sensitivity. Indeed, we are facing several challenges: how to insert a substance within the material? If wood is impregnated, what is the amount of the substance which has recrystallized (if any)? Will it be possible to use NQR as a sensor? This paper is devoted to these questions. For simplicity, we have chosen a molecule often used as a model in Nitrogen14 Quadrupole Resonance, namely sodium nitrite $\mathrm{NaNO}_{2}$. It has the further advantage of being soluble in water and can be considered as bio-compatible in certain circumstances (food preservation).

\section{Experimental}

\section{Impregnation}

Small cylindrical pieces of wood of $70 \mathrm{~mm}$ height and $8 \mathrm{~mm}$ diameter were machined so that they could fit into $10 \mathrm{~mm}$ o.d. tubes (employed for NMR measurements). They were impregnated with a saturated aqueous solution of sodium nitrite with the help of a specially constructed device (figure 1). Impregnation can be possibly performed under high pressure (up to 15 bar) ${ }^{1}$, but also under partial vacuum. We mean by "partial vacuum” soft pumping of the vessel containing the wood rod immersed in the aqueous solution of sodium nitrite. This has the virtue of removing air thus facilitating the impregnation process. In the case of impregnation "under high pressure”, pumping is first applied to the wood rod (again for removing air) and then the rod is immersed in the pressurised aqueous solution. Only raw material (without any preparation prior to impregnation) led to significant results (see below). 
Wood samples were impregnated for 48 hours. They were subsequently dried either out in the open (ambient temperature and moisture) or in a dry kiln at $103^{\circ} \mathrm{C}$ (highest limit before wood degradation $^{2}$ ) for a stabilization period (controlled by weighing at regular intervals) which generally did not exceed 48 hours.

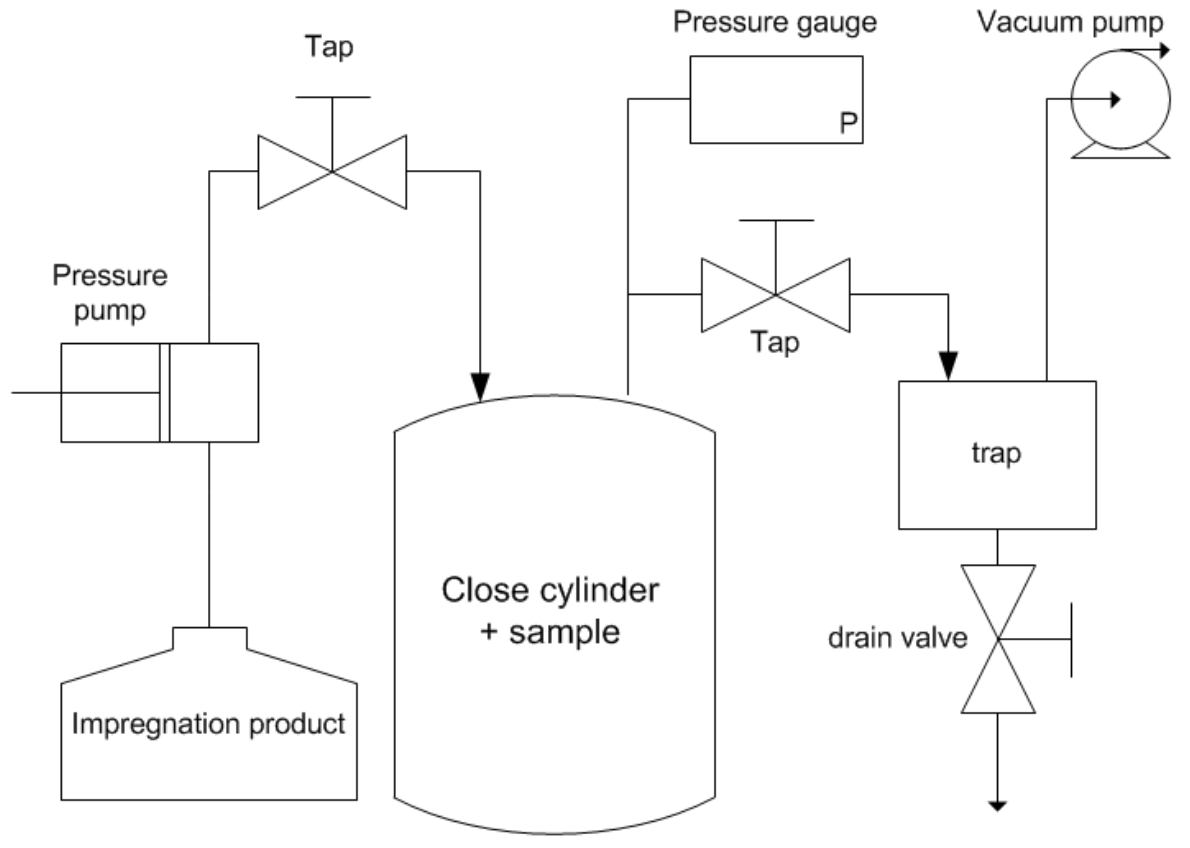

Figure 1. Block diagram of the impregnation device.

\section{Nitogen-14 Quadrupole Resonance}

$\mathrm{NQR}$ experiments were carried out at $4.64 \mathrm{MHz}$ (the highest resonance frequency of $\mathrm{NaNO}_{2}$ ) and at ambient temperature with a home-made spectrometer described previously ${ }^{3}$. For the most recent measurements, a new probe was constructed: still with a solenoidal coil surrounding the sample but with a cylindrical shield at a distance of $8 \mathrm{~cm}$ from the solenoid center. This prevents electromagnetic reflections thus parasitic capacitors which exist in the previous probes. Also, tuning and matching of this probe involve equilibrated circuits. All measurements reported here have been performed with a simple low power pulse of $100 \mu$ s duration (corresponding to the first maximum of the nutation curve). A dead time (between 
the end of the pulse and the beginning of acquisition) of $300 \mu$ s along with low power pulses avoids baseline distortions. A repetition delay of $0.5 \mathrm{~s}$ was allowed between two consecutive acquisitions. Typically, with this new probe, 4096 transients were accumulated but, as shown later, much less accumulation can be envisioned.

\section{Results}

It was almost a surprise to observe a NQR signal in most impregnated wood samples. This implies that, within this material, sodium nitrite has recrystallized upon drying. Moreover, relatively sharp lines indicate few (if any) defects in the lattice. Such experiments proved to be successful for almost all species that we have tried. Spectra are reported in figure 2.

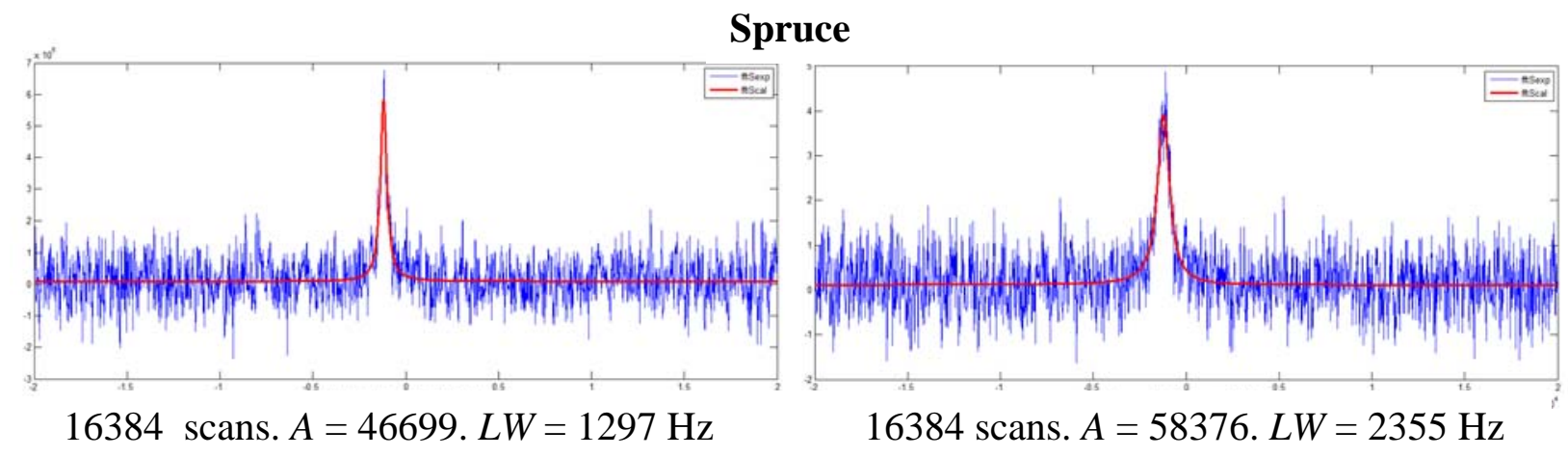

Sylvester pine

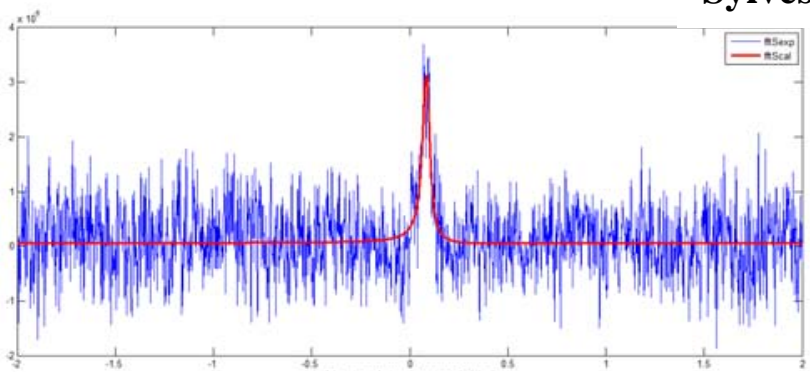

16384 scans. $A=27813 . L W=1397 \mathrm{~Hz}$

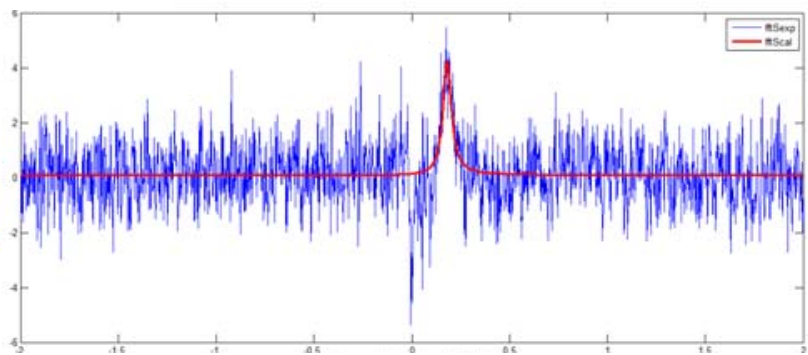

16384 scans. $A=42160 \mathrm{LW}=1568 \mathrm{~Hz}$

\section{Beech}

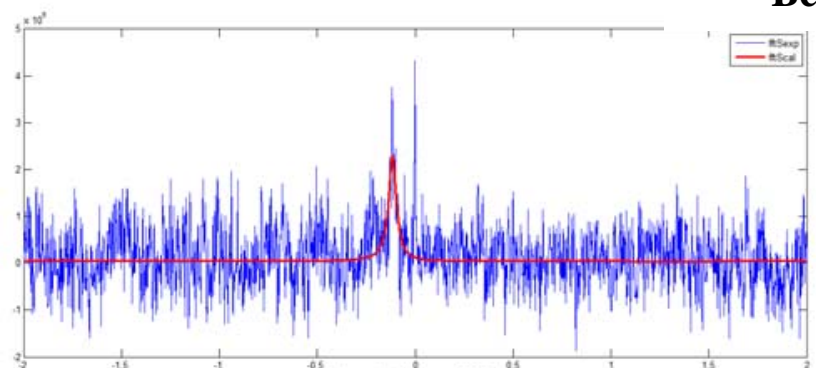

16384 scans. $A=21181 . L W=1458 \mathrm{~Hz}$

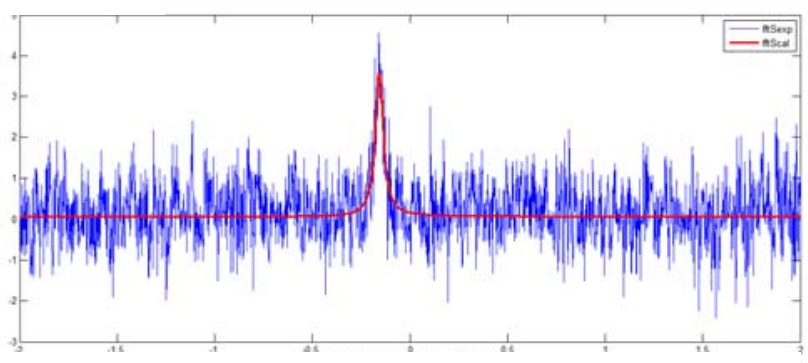

16384 scans. $A=34626 . L W=1519 \mathrm{~Hz}$ 
Ash

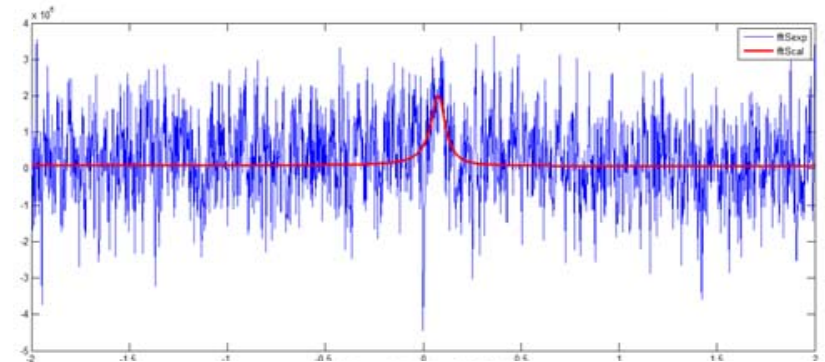

65536 scans. $A=8534 . L W=2823 \mathrm{~Hz}$

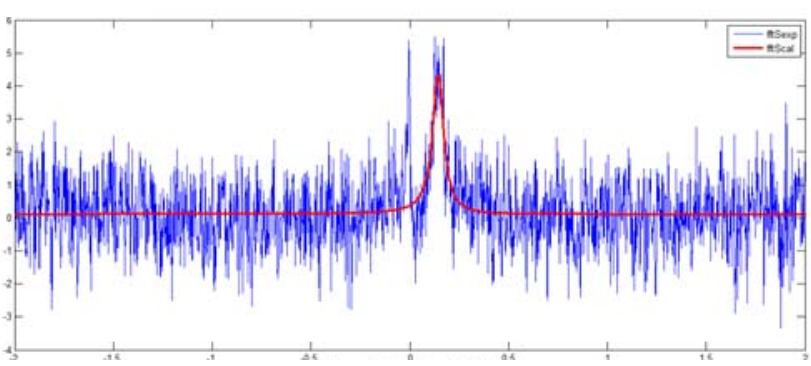

65536 scans. $A=14202 . L W=2109 \mathrm{~Hz}$

Oak

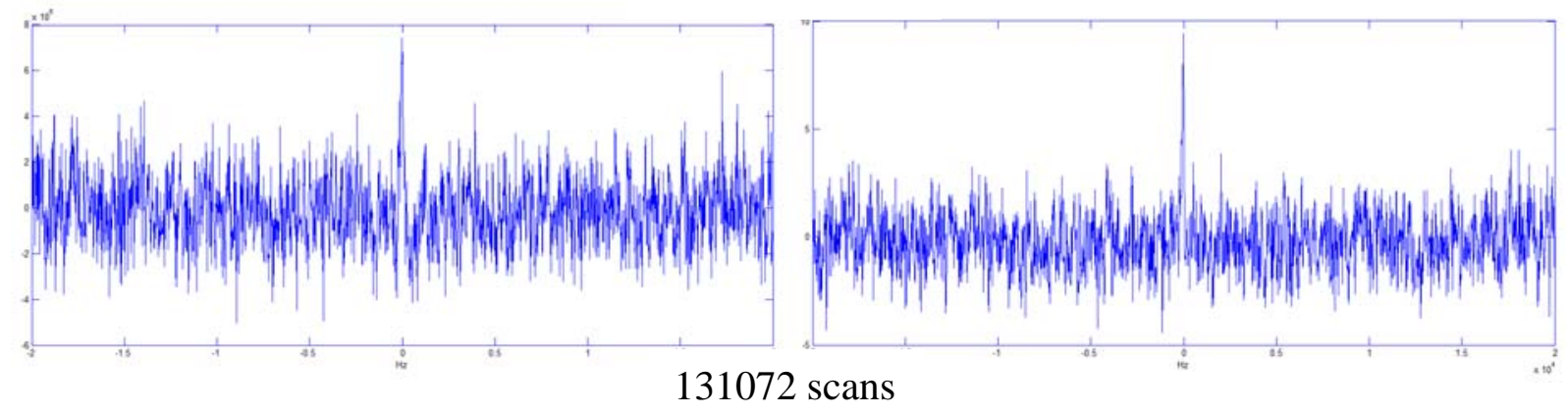

Figure 2. 4.64 MHz spectra of recrystallized $\mathrm{NaNO}_{2}$ in different wood species (impregnation under partial vacuum) with the two drying modes described in the text. Left column: out in the open; right column: dry kiln. Continuous curves (in red) correspond to recalculated spectra (see below). A stands for the peak area normalized to 4096 scans whereas $L W$ is the line-width at half-height.

The first obvious observation concerns the ability of the different species to be impregnated by aqueous solutions of sodium nitrite. This can be quantified by the peak area in either of the two series, thus by the amount of recrystallized $\mathrm{NaNO}_{2}$. This impregnation ability is in the order spruce $>$ Sylvester pine $>$ beech $>$ ash $>$ oak (for the latter, we just observe the spike at zero frequency and it is indeed well known that oak is difficult to impregnate ${ }^{4}$ ). Two other properties concern the drying mode: less $\mathrm{NaNO}_{2}$ is recrystallized in the case "out in the open" while line-widths are smaller than in the case “dry kiln”. The interpretation of the first feature is immediate: upon heating at a higher temperature, more water is eliminated. The second feature can be explained by the fact that taking the material at a relatively elevated temperature modifies its structure entailing some defects in the crystal lattice of $\mathrm{NaNO}_{2}{ }^{5}$ (due to possible interactions of $\mathrm{NaNO}_{2}$ with the material). Notice that these early experiments have 
been performed with the old probe. In fact, the above trends have been confirmed by accurate measurements carried out with the new probe on spruce samples. Relevant spectra are shown in figure 3.

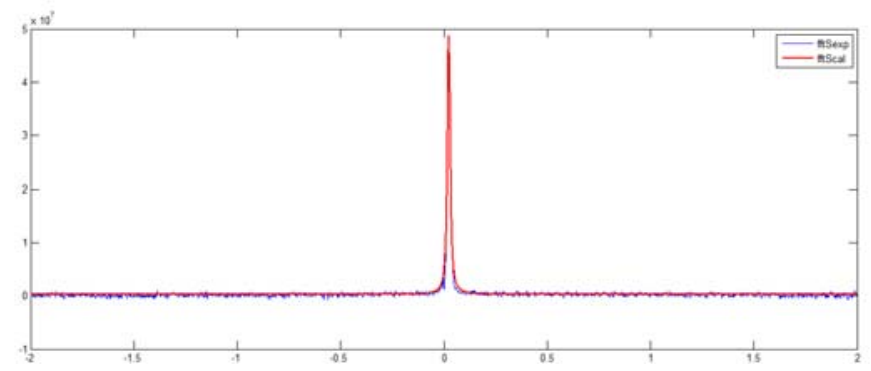

512 scans. $A=2319450 . L W=478 \mathrm{~Hz}$

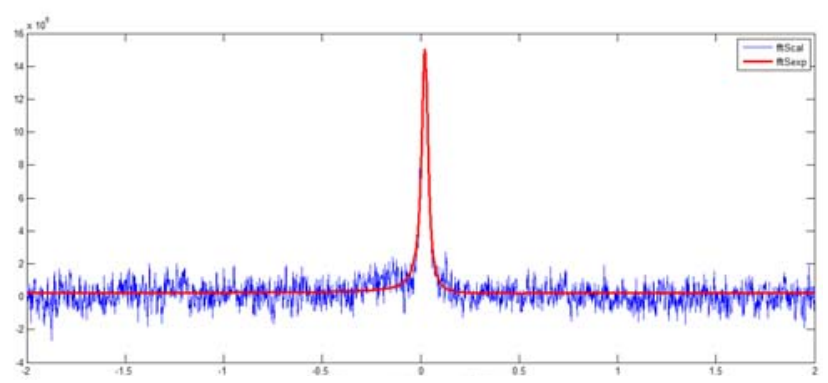

4096 scans. $A=456477 . L W=1232 \mathrm{~Hz}$

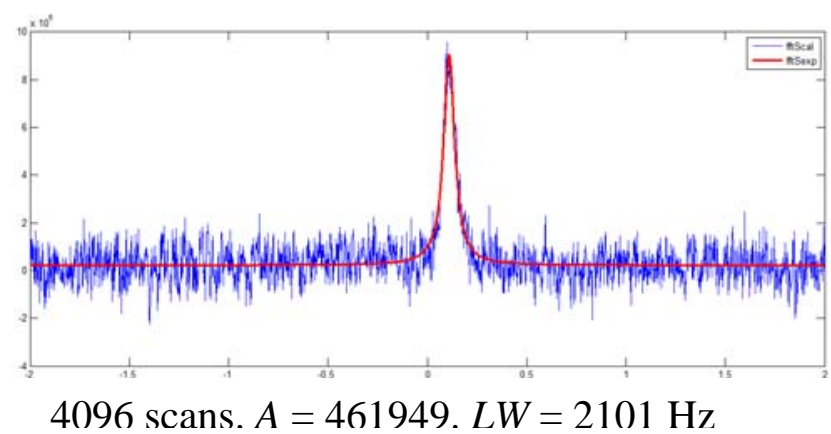

4096 scans. $A=461949 . L W=2101 \mathrm{~Hz}$

Figure 3. 4.64 MHz spectra of $\mathrm{NaNO}_{2}$ obtained with the new probe. Top: reference spectrum of a $\mathrm{NaNO}_{2}$ powder sample of the same size as the spruce samples (bottom). Impregnation was carried out under partial vacuum. Left: out in the open; right: dry kiln. Continuous curves (in red) correspond to recalculated spectra (see below). A stands for the peak area normalized to 4096 scans whereas $L W$ is the line-width at half height.

It can be seen that the amount of recrystallized $\mathrm{NaNO}_{2}$ is hardly larger when the sample has been subjected to the dry kiln. This was already recognized in figure 2 but seems to be specific of spruce (for other species, less $\mathrm{NaNO}_{2}$ is recrystallised out in the open). This amount, as determined by peak areas (the quantities $A$ ), is five times larger in the powder than in wood. From the weight of $\mathrm{NaNO}_{2}$ in the powder sample, we arrive at the absolute weight of $\mathrm{NaNO}_{2}$ in the spruce sample (650 mg). It turns out that this value coincides almost perfectly with weighing data (before impregnation and after drying). The next issue is evidently the line-width of the recrystallized $\mathrm{NaNO}_{2} \mathrm{NQR}$ signal. In the case of spruce, there is an order of magnitude when going from crystallized powder to $\mathrm{NaNO}_{2}$ recrystallized in wood (with 
drying “out in the open”). As already mentioned, this can be reasonably attributed to defects in the crystalline lattice which arise from interactions with the material. These defects are still more important (line-width increases by a factor of two) when drying is carried out in a kiln. As assumed above, this is very likely due to structural modifications within the material and thus to modifications of the interactions with $\mathrm{NaNO}_{2}$.

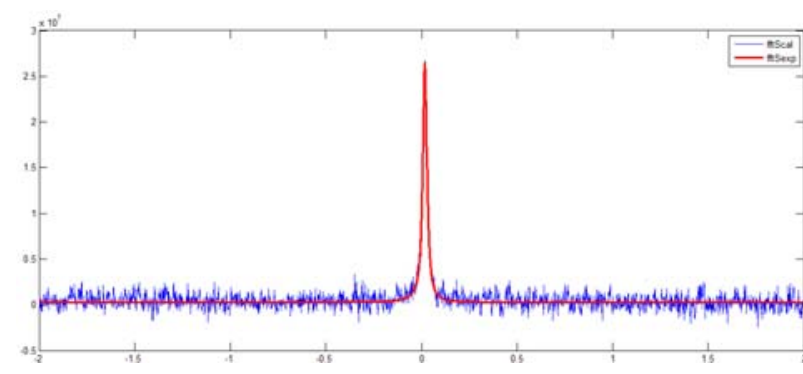

4096 scans. $A=529148 . L W=807 \mathrm{~Hz}$

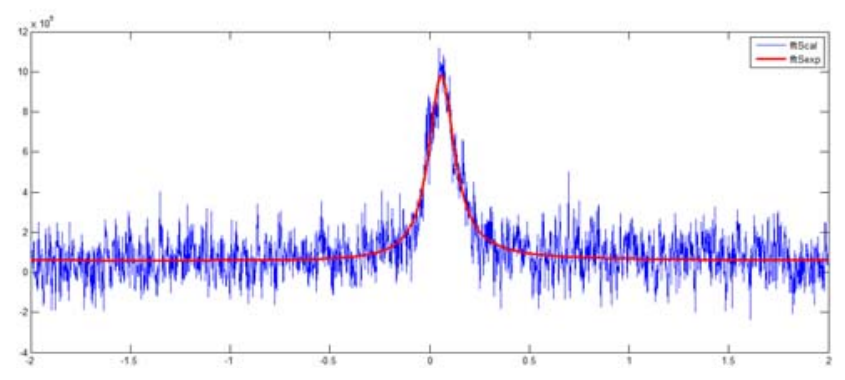

4096 scans. $A=1134670 . L W=4904 \mathrm{~Hz}$

Figure 4. 4.64 MHz spectra of $\mathrm{NaNO}_{2}$ in spruce. Impregnation was carried out under a pressure of 15 bars. Left: drying out in the open; right: drying in the kiln. Continuous curves (in red) correspond to recalculated spectra (see below). A stands for the peak area normalized to 4096 scans whereas $L W$ is the line-width at half height.

In order to increase the amount of $\mathrm{NaNO}_{2}$ in wood, impregnation was achieved under a pressure of 15 bars $^{6}$ (see figure 1). The spectra obtained subsequently to drying are displayed in figure 4. They are quite different from those corresponding to impregnation under partial vacuum. In the case of drying "out in the open”, we observe a sharper line and roughly the same amount of recrystallized $\mathrm{NaNO}_{2}$. Conversely, when the sample has been dried in the kiln, the line-width increases considerably and the amount of recrystallized $\mathrm{NaNO}_{2}$ is roughly twice that of the sample impregnated under partial vacuum. On the other hand, weighing the sample before impregnation and after drying in the kiln indicates that the quasi totality of sodium nitrite corresponds to the $A$ value of the right spectrum of figure 4. Again, these observations can be interpreted by invoking interactions between $\mathrm{NaNO}_{2}$ and wood. When the sample has dried “out in the open”, only a part of water is taken off (probably the part near the surface as for samples which have been impregnated under partial vacuum), leaving a limited 
quantity of recrystallized $\mathrm{NaNO}_{2}$ (about half the total amount of sodium nitrite). It is observed that the line-width is even weaker than in the case of impregnation under partial vacuum. This means that the interactions of recrystallized $\mathrm{NaNO}_{2}$ with the material are weakened due to the impregnation mode. Conversely, as all water has been eliminated by the drying process in the kiln (see above), and owing to the large line-width (right spectrum of figure 4), we can infer that the spruce sample was impregnated to the core and that high pressure has contributed to alter the material and, as a consequence, to enhance the interactions undergone by sodium nitrite. Indeed, alteration of the material is especially deleterious when, prior to impregnation, the piece of wood is dried in the kiln. This procedure was attempted, again with the hope to increase the amount of recystallized sodium nitrite ${ }^{7}$. It turns out that, in these conditions, we totally failed to observe any NQR signal (with impregnation under partial vacuum or under high pressure). This could mean that water, which is naturally present in wood, is necessary for keeping a structure prone to recrystallization of embedded sodium nitrite.

Finally, we have checked that, when sodium nitrite recrystallizes in wood, its NQR spectrum remains the same for months and probably longer.

\section{Data analysis}

All results, in terms of peak area $(A)$ or line-width at half-height $(L W)$, which have been given until now have been obtained through the procedure described below.

As seen above, obtaining a spectrum with a suitable signal-to-noise ratio $(\mathrm{S} / \mathrm{N})$ requires the accumulation of a large number of transients. Let us recall that the spectrum (frequency domain) results from the Fourier transform of accumulated free induction decays (fids; time domain). As a consequence, when the NQR line is relatively broad, the S/N is evidently lowered. Hence, a better strategy is to look at the time domain data since the parameter of interest is the amplitude $A$ of the fid (which is also the peak area in the frequency domain) 
while the fid damping factor is related to the line-width $(L W)$ in the frequency domain. It is also important to realize that, in our case, the spectrum involves a single line, this point facilitating any fitting procedure.
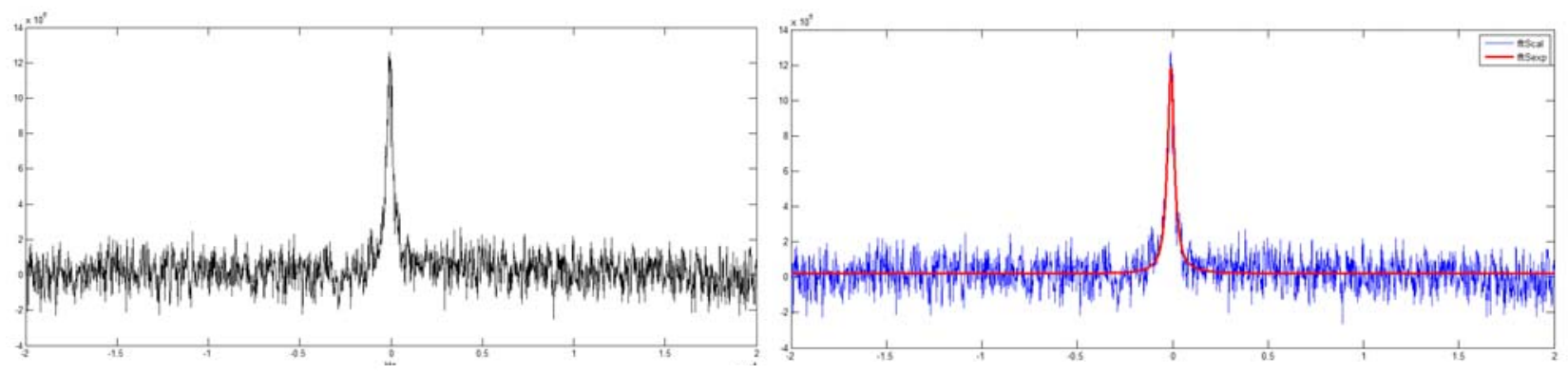

4096 scans (half an hour). $A=390851 . L W=1336 \mathrm{~Hz}$
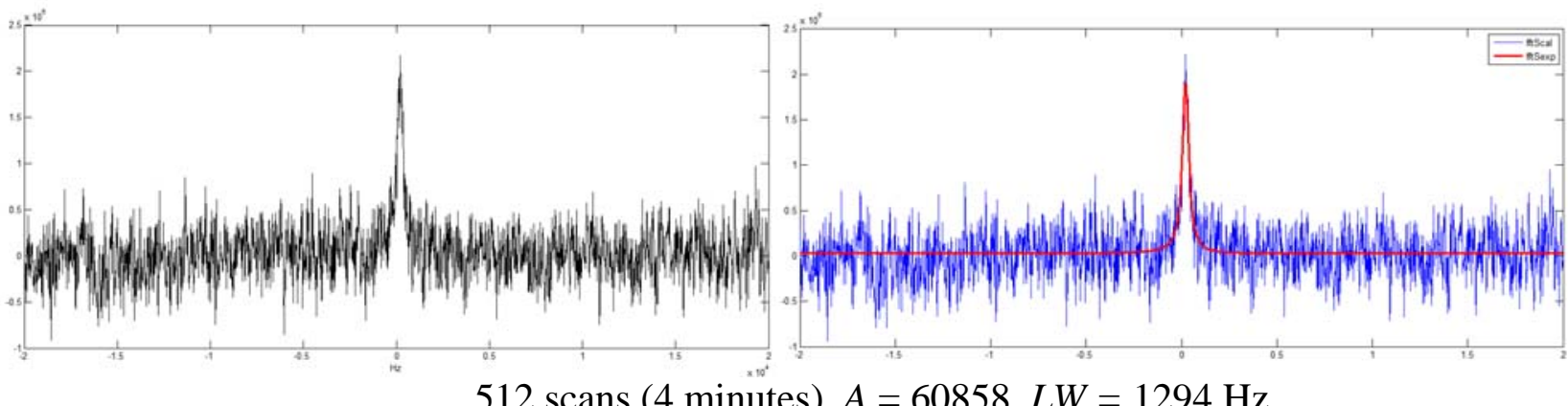

512 scans (4 minutes). $A=60858 . L W=1294 \mathrm{~Hz}$
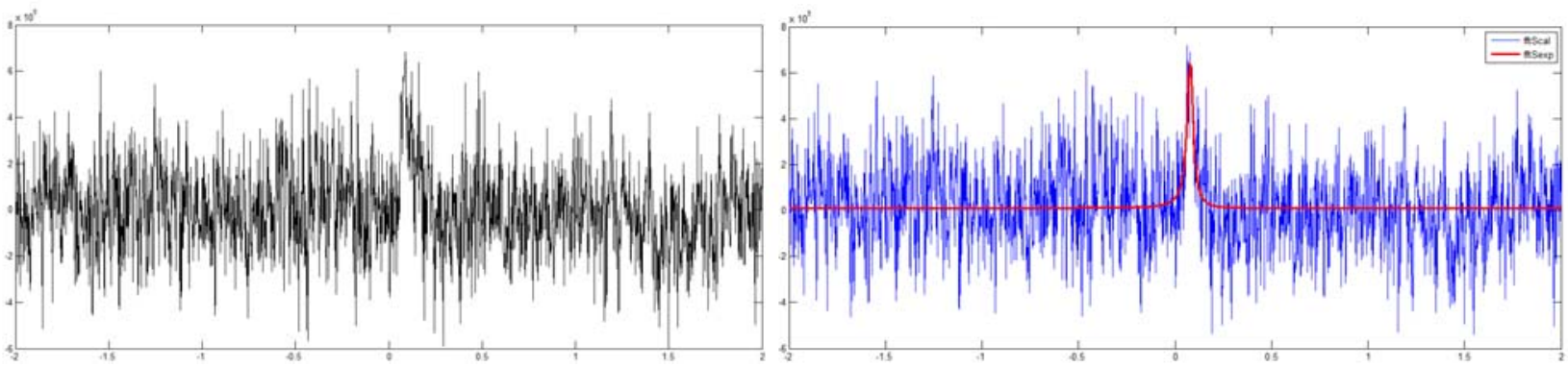

128 scans ( 1 minute). $A=19450 . L W=1230 \mathrm{~Hz}$
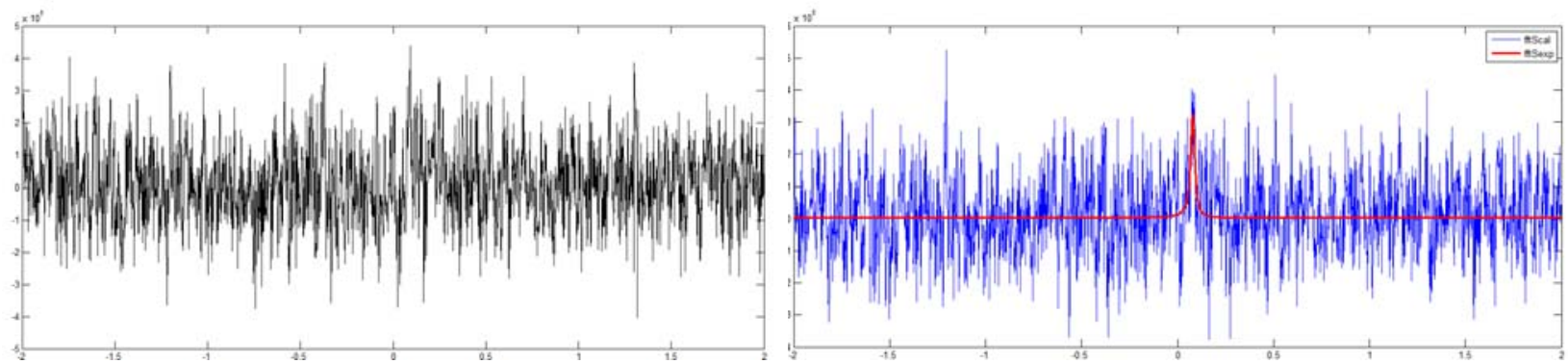

64 scans (30 seconds). $A=6483 . L W=809 \mathrm{~Hz}$

Figure 5. 4.64 MHz spectra of $\mathrm{NaNO}_{2}$ in spruce (impregnation under partial vacuum; drying out in the open. Left column: raw spectra. Right column; the same raw spectra with the reconstructed spectra (continuous curves in red) with parameters derived from time domain data fitting. 
In figure 5 are gathered a series of spectra (frequency domain) as a function of the number of scans (or, equivalently, as a function of the measuring time). Of course, with 4096 scans (half an hour of measuring time) the peak is perfectly defined with an excellent S/N. 512 scans (4 minutes of measuring time) appear convenient for properly observing the $\mathrm{NaNO}_{2}$ peak. However, for future applications, this measuring time might still be too long. With one minute measuring time, we can guess the presence of a peak but this is no longer true for a measuring time of 30 seconds.

Now, we are going to show that a simple non linear least squares (NLLS) fitting procedure applied to the time domain data (fid) is able not only to reveal the presence of a peak but also to provide reliably the parameters of interest, namely $A$ and $L W$. Such least-squares procedures are relatively common in multiline NMR spectra ${ }^{8,9}$ and make use of the following mathematical model for the fid (in the case of a single line and assuming that the fid is devoid of any dc component)

$$
S(t)=A \exp \left(2 i \pi v_{0} t\right) \exp (i \varphi) \exp [-\pi(L W) t]
$$

The parameters $A$ and $L W$ have been defined earlier; $v_{0}$ is the resonance frequency with respect to the carrier frequency and $\varphi$ the phase factor. Alternatively the damping function $\exp [-\pi(L W) t]$ can be replaced by a Gaussian function. A dedicated software has been developed under MATLAB. It requires starting values for these four parameters and provides refined values along with reconstructed spectrum in the frequency domain. The strating values can be derived from the experimental spectrum if it is sufficiently legible. Otherwise, as the spectral parameters of the considered NQR signal can be relatively easily guessed, they can be used manually as input parameters. As shown in the right column of figure 5, reconstructed spectra ere perfectly consistent with spectra obtained from Fourier transform of the experimental fids. It was even possible to detect, thanks to the fitting of time domain data, a signal which is invisible in the frequency domain (bottom spectra of figure 5). The $A$ values 
are, as expected, approximately proportional to the number of scans while $L W$ values remain of the same order of magnitude.

\section{Conclusion}

When this project started, it was considered as very challenging and rather utopian. The first result was looked at with some mistrust because it required extensive time averaging (several hours) and involved some artefacts. In fact, with some tenacity, several instrumental improvements and with appropriate data processing, we were able to obtain very consistent and reproducible results in a very reasonable measuring time (lower limit: 30 seconds). Extensive studies of spruce impregnated by sodium nitrite as a function of impregnation and drying conditions have shown that heating always modify the wood structure, as reflected by the $\mathrm{NaNO}_{2}$ signal line-width. This latter property is indicative of interactions between the $\mathrm{NaNO}_{2}$ crystal lattice and the material. In particular, it was noticed that drying wood at elevated temperature prior to impregnation totally precludes the formation of $\mathrm{NaNO}_{2}$ crystals. Otherwise, it was shown that in soft conditions (without going to elevated temperatures), a large amount of $\mathrm{NaNO}_{2}$ could be recrystallized in spruce wood. This opens the way of material labelling by nitrogen containing compounds and its further detection by nitrogen-14 Quadrupole Resonance.

\section{References}

1. Malkov S, Tikka P, Gullischen J, Towards complete impregnation of wood chips with aqueous solutions. Paper and Timber 83, 468 (2001)

2. Norme NF B516004, Bois-détermination de l’humidité, AFNOR, Paris, A985

3. Hiblot N, Cordier B, Ferrari M, Retournard A, Grandclaude D, Bedet J, Leclerc S, Canet D. A fully home-made N-14 quadrupole resonance spectrometer, C.R. Chimie 11, 568 (2008)

4. Humar M, Zlindra D, Pohleven F, Influence of wood species, treatment method and biocides concentration on leaching of copper-ethanolamine preservatives. Building and Environment 42, 578 (2007)

5. Buess M L, Caulder S M, Factor affecting the NQR line width in nitramine explosives. Appl. Magn. Reson. 25, 383 (2004) 
6. Siau J F, Shaw J S, The treatability of refractory softwoods. Wood and Fiber 3, 1 (1971)

7. Matsumura J, Booker R, Ridoutt B, Donaldson N, Mikajiri N, Matsunaga H, Oda K, Impregnation of radiate pine wood by vacuum treatment: effect of pre-steaming on wood structure and resin content. The Japan wood research society 45, 456 (1999)

8. Barkhuijsen H, de Beer R, Bovée W M M J, van Ormondt D, retrieval of frequencies, amplitudes, damping factors and phases from time domain signals using a linear least-squares procedure. J. Magn. Reson. 61, 465 (1985)

9. Montigny F, Brondeau J, Canet D, Analysis of time domain NMR data by standard non linear least-squares. Chem. Phys. Lett. 170, 175 (1990) 